\title{
When More Voltage Means More Distance
}

\author{
The Limits of Long-Distance Electric Power Transmission in Terms of Today and Tomorrow \\ By Dr. Charles P. Steinmetz
}

Chief Consulting Engineer, General Electric Company

W HEN about 40 years ago, Edison first transmitted at constant pressure, that volts and soon afterward 220 volts. At this electrical pressure or voltage, electricits can be sent economically for about half a mile to a mile, and when it becomes desired to send electric power ove longer distances, higher voltages, that is, higher electrical pressures, become necessary, just as a higher water pressure or higher air pressure is necessary to send water or air over a greater distance.

Thus steadily in these 40 years, transmission voltage have been increased, until now we are beginning to use 220,000 volts, a pressure just 1000 times as high as that considered the highest safe pressure only 40 years ago.

The question, which the layman always asks, is, "How far can electricity be transmitted economically?"

Suppose we want to double the distance to which to send the electric power. This means twice as long a transmission line, and twice the cost. Therefore, to have the same economy, that is, the same transmission line cost per horsepower of electric energy sent over it we have to send twice as much power over the line of twice the length. Suppose then we use the same electric current but twice the voltage to get twice the power. With the same current, the loss of power per mile of line would be the same, and as the line is now twice as long, the total los of power would be doubled, and as twice as much powe is sent over the line, the loss per horsepower of energy sent over the line is the same, that is, the efficienc of transmission is the same as before.

We see thus, that by increasing the voltage or electric pressure, and the power sent over an electric transmission line, in proportion to the distance of transmission, that is, to the length of the line, we get the same efficiency and the same economy, that is, the same percentage loss of the transmitted power, and the same (approximate) cost per horsepower transwitted.

If then at 220 rolts electricity could be transmitted economically over one-half to one mile, at a thousand times that voltage, or 220,000 volts, as now used, it could be transmitted economically over a thousand times the distance, that is, 500 to 1000 miles, and if 100 horsepower could be transmitted at 220 volts we would have to transmit 100,000 horsepower at 220,000 volts.

As for 100,000 horsepower the generating system, etc. is cheaper per horsepower, and more efficient, than for 100 horsepower, we could in the former case allow a greater cost and greater loss per horsepower in the line, and still get the same total efficiency and economy of the system, and this would allow us to economically transmit the electric power over more than 1000 miles' distance.

Hereby all the big cities of the Atlantic seaboard and of the Middle West, New York, Boston, Philadelphia, Baltimore, Washington, Chicago, St Louis, Pittsburgh, would be well within the radius of economical power transmission from Niagara Falls, with the present means and methods, that is, without going beyond what present experience has established as good practice.

It is not probable however that electric power would ever be sent from Niagara Falls to New York or any other of these cities, for the simple reason that in the ndustrial East all the millions of horsepower of electric energy which Niagara could deliver, even if completely developed, would find a market and would be consumed within a few hundred miles of Niagara long before the present day electrical limits of trans mission are reached, and obviously nobody would build transmission lines to send the power over thousands of miles, when he could find a market for his power within a few hundred miles.

The question of the maximum distance over which electric power can be transmitted, therefore, has almost entirely eliminated itself as a serious engineering problem, and while electricity could be transmitted economically in large bulk, if so desired, for over a thousand miles, even with the largest water powers, with rare exception, all the available water power will be taken up, and find a market, long before the electrical limits of transmission are reached. days and as the layman looks at it still today, that is, transmission from a water power over a long line to consumer, such as a city, etc.

But our present day transmission lines are almost always distribution circuits and interconnecting cir cuits, that is to say they form a part of a network of electric lines, which link together various sources of electric power, water powers and steam powers, and the various places of consumption, cities, mines, factories and mills, and so forth. That is, a network of electric lines begins to cover the country similar to the network of railway tracks, and while the network of railway tracks, built three-quarters of a century ago, takes care of the transportation, distribution and supply of all the materials, so now a network of electric lines is being developed and is spreading all over the country of so adequate a volume as to take care of the transmission, the distribution and the supply as the second essential necessity of our civilization.

A New Carburetor for Light Oils

A NEW apparatus invent A ed by á Frenchman, $M$ de Maumy, makes it possible to operate a motor by means of coal-tar oils or alcohol or a mixture of the two. It principle consists in a feed operating by an automatic gage so as to maintain a constant charge of the atomizers without any previous heating of the liquid. The atomizer works by a lapping or licking motion lowering the pressure in the cylinder during the intake, causing a flow of air which laps a cylinder with an undulating surface; the oil is sucked in violently, being atomized by shocks and thus enters the cylinder. The intake of air should be somewhat retarded, and this retardation is obtained by a modification of the cams of admission. The mixture is ignited by an ordinary motor spark plug and it begins to work instantaneously either with alcohol, kith lierosene, or with coaltar oils. Upon being tested the apparatus worked admirably. It is very simple in construction, requiring neither a pump nor any sort of heating apparatus.

There is no carbonization of the cylinders even when coal-tar oils are used for fuel, and the negligible amount of

line in Southern California

One of these exceptions is the Pacific Coast. There the water powers are located inland, in the mountain while the foremost market for the power is in the big cities along the seacoast. The transmission thus is all in one direction, from the east to the west, and little market for the power is near the source of power, little power found near the places of foremost power consumption.

It is a very significant and well-demonstrated fact that the highest transmission voltages, 150,000 to 220,000 volts, are found in California.

Another instance might be the transmission of the power of Victoria Falls in South Africa to the Rand, over 700 miles. However, it is quite possible that before this transmission is built, the country will have developed so far as to afford a market nearer than the Rand, and the experience of Niagara Falls will repeat itself.

Thus today there is very little electrical power transmission of the form as understood in the early smoke given off shows that the combustion is excellent. This apparatus, which is ca-

,000-volt transmission low compression can be appable of functioning at a without difficulty to nearly all gasoline motors plied without difficulty to nearly all gasoline motors
It has the considerable advantages over Diesel and semi-Diesel motors of being less complicated, less cumbrous, and quite safe; moreover, the upkeep costs nothing.

At the same time it is possible to make use of inferior and lower priced fuel with an efficiency almost as economical in high speed motors as well as in slowe ones without making it necessary to purchase a special high compression motor, which would inevitably add considerably to the weight, to say nothing of the high price, the difficulty of transport and other features that need not be mentioned but which have to be considered.

These entirely new processes denote a marked advance in the solution of the problem involved in the substitution of crude oils and of alcohol for gasoline, so that they will undoubtedly rapidly come into general use. 